\title{
A retinoic acid-inducible skin-specific gene (RIS-1/psoriasin): molecular cloning and analysis of gene expression in human skin in vivo and cultured skin cells in vitro
}

\author{
Amir Tavakkol, Christos C. Zouboulis, Elizabeth A. Duell \& John J. Voorhees \\ Department of Dermatology, University of Michigan Medical Center, Ann Arbor, MI 48109, USA \\ Address for correspondence: Preclinical Dermatology Research, Hoffmann-La Roche, Inc., Rm. 710, Bldg. 86, \\ 340 Kingsland Street, Nutley, NJ 07110-1199, USA
}

Received 21 July 1994; accepted 23 September 1994

Key words: retinoic acid, skin, differential hybridization, cloning, keratinocytes, gene expression

\begin{abstract}
A retinoic acid (RA) inducible skin-specific gene transcript (RIS-1) was isolated by differential hybridization screening of a RA-treated human skin cDNA library. The library was constructed from pooled RNA derived from normal adult human skin treated with all trans-RA for $4 \mathrm{~h}(\mathrm{n}=6)$ and $12 \mathrm{~h}(\mathrm{n}=6)$ in vivo. RIS-1 cDNA corresponded to a $0.6 \mathrm{~kb}$ transcript that was barely detectable in normal adult human skin but was significantly induced by $8 \mathrm{~h}$ in RA-treated compared to vehicle-treated skin (range 1.1-3.6 fold). Prolonged RA treatment for up to $24 \mathrm{~h}$ further increased relative RIS-1 mRNA levels by 1.3-5.5 fold. HPLC analysis of the RA content of $0.1 \%$ RA-treated skin in vivo revealed significant levels at $6 \mathrm{~h}(18.8-120.6 \mathrm{ng} \mathrm{RA} / \mathrm{g}$ wet weight tissue; approximately $240 \mathrm{nM}$ ), immediately preceding the time point at which the increased RIS-1 mRNA level was first seen. This concentration of RA also induced the mRNA levels for cellular RA binding protein II (1.6-19 fold), a marker of RA activity in human skin. RIS- 1 mRNA was detected by Northern and dot blotting only in normal skin but not in any other normal human tissues examined, indicating a tissue-specific pattern of gene expression. RIS- 1 transcripts were detected at very low levels in untreated cultured human epidermal keratinocytes, while no expression was seen in dermal fibroblasts and melanocytes, the other major cell types in skin. Southern analysis of human and mouse DNA indicated the existence of evolutionarily conserved sequences for RIS-1 between these two species. The polypeptide sequence derived from the partial RIS-1 cDNA was found to be identical to the calcium binding domain found in 'psoriasin', a gene whose expression appears to be increased in the skin of psoriasis patients.
\end{abstract}

Abbreviations: RIS-1 = retinoic acid-inducible skin-specific gene; RA = All-trans retinoic acid.

\section{Introduction}

All-trans retinoic acid (RA) induces a characteristic set of biochemical and histological changes when applied to human skin [1] and is used topically to treat a variety of cutaneous diseases [2]. However, the cellular and molecular mechanism(s) by which topical RA treatment induces cutaneous changes is largely unknown. The recent discovery of two distinct families of nuclear RA receptors, the retinoic acid receptors (RAR) and the retinoid $\mathrm{X}$ receptors ( $\mathrm{RXR}$ ), has provided a possible explanation for the pleiotypic effects of $\mathrm{RA}$ in human skin $[3,4]$. These receptors transcriptionally activate target genes by cooperative binding to the RA response element (RARE) [5]. The RARE, a specific DNA sequence motif, or a closely related one, originally identified in the RAR-beta promoter, binds RAR/RXR heterodimers and is responsible for the RAmediated activation of RA response genes. Due to their specific pattern of expression, it has been suggested that each RAR or RXR might have its own specific function depending on the tissue and cell types in which they are expressed [6]. 
We and others have demonstrated RAR and RXR gene expression in adult human skin and in cultured cells derived from human epidermis and dermis [7-9]. This expression is compatible with RAR/RXR mediation of at least some RA regulation of gene expression in human skin. No variation has been found in the expression of the various RARs and one of the RXR isoforms in RA topically-treated skin in vivo [7-9], or cultured human keratinocytes in vitro [8], suggesting the possible involvement of additional cell or tissue specific factors in RA-mediated skin response. Another class of proteins known to be regulated by RA includes the family of cytosolic RA binding proteins, CRABP-I and $I[10,11]$. We and others have recently shown that CRABP-II transcripts are expressed in adult human skin $[12,13]$. CRABP-II mRNA is markedly induced in normal human skin [7], and mouse skin by topical RA and its synthetic analogs [14]. However, CRABPII appears to regulate the amount of free RA available to activate RAR/RXR transcriptional activators [15], rather than directly mediating the effects of RA.

Other RARE containing RA response genes include growth hormone [16], phosphoenolpyruvate carboxykinase [17], Era-1/HOX 1.6 [18], and alcohol dehydrogenase [19]. Although, these genes may have important functions in embryonic development, metabolic pathways and cellular homeostasis [for review see 20], they are either not expressed in adult human skin or are not responsive to topical RA.

Therefore, the question of which genes are direct targets of RA action in skin and how this regulation is effected remains an important but unresolved issue. As an initial step towards identifying RA early response genes in skin, we have utilized the differential screening of a cDNA library constructed from RA-treated human skin. We report here the cloning and characterization of a cDNA whose mRNA level increases rapidly within 6-8 h in RA-treated skin in vivo, indicating that it represents a skin-specific early RA response gene.

\section{Materials and methods}

\section{Adult human epidermal samples}

After obtaining informed consent, adjacent skin areas $(9 \times 3 \mathrm{~cm})$ of the buttocks of healthy volunteers were treated for $4 \mathrm{~h}$ to $48 \mathrm{~h}$ with a single dose of approximately 500 mg RA cream $\left(0.1 \%\right.$ Retin $\left.A^{\circledR}\right)$ and its vehicle cream (Ortho Pharmaceutical Corp., Raritan,
NJ) under occlusion with plastic wrap [1]. Keratome biopsies ( $0.2 \mathrm{~mm}$ thick) were then obtained under local anaesthesia with $1 \%$ lidocaine, immediately frozen in liquid nitrogen and stored at $-70{ }^{\circ} \mathrm{C}$ until use. The biopsies contained primarily $90-95 \%$ keratinocytes, the remaining cell types being melanocytes, fibroblasts, endothelial and Langerhans cells [1]. Protocols for human subjects were previously approved by the University of Michigan Institutional Review Board.

\section{Measurement of RA concentration in skin samples}

Prior to keratome biopsy, stratum corneum was removed by tape stripping of intact skin to avoid elevated RA amounts due to its trapping by stratum corneum. The extent of the removal of the stratum corneum was monitored by microscopic examination of parallel 4-mm punch specimens of tape-stripped skin as described [21]. The tape-stripped biopsies were weighed, powdered and immediately transferred into $\mathrm{CHCl}_{3}: \mathrm{CH}_{3} \mathrm{OH}(2: 1)$ containing tracer amounts of ${ }^{3} \mathrm{H}$ RA (DuPont NEN, Boston, MA). After extraction, the RA content was analyzed by HPLC essentially as described [21]. Protein measurements were carried out by method of Lowry [22].

\section{Cell cultures, RNA isolation. Northern \& dot blotting}

Human dermal fibroblasts, epidermal keratinocytes and melanocytes were cultured as described [23]. Preparation of RNA from skin biopsies and cultured cells as well as Northern blotting were as previously described [23]. The human multiple tissue RNA blot (MTN) was obtained from Clonetech Laboratories (Cat. \#7760-1, Palo Alto, CA). The dot blot was prepared, using a microsample filtration manifold (Schleicher and Schuell, Keene, NH) and manufacturer's recommendations. All blots were hybridized with random-primed ${ }^{32} \mathrm{P}$-labeled cDNA probes [23] and RNA blots were quantitated after $24 \mathrm{~h}$ exposure using a PhosphorImager (Molecular Dynamics, Sunnyvale, CA) [23]. As an internal control for quantitation of mRNA levels in RNA blots, a cDNA encoding the human acidic phosphoprotein PO (36B4) was simultaneously hybridized to all Northern blots [23]. $36 \mathrm{~B} 4$ is derived from epithelial MCF-7 cells and is believed to be under translational control [24]. In some experiments, cyclophilin cDNA [25] was used as control gene. No differences were observed between 36B4 and cyclophilin mRNA levels in either RA- or vehicle- 
treated skin. For RNA loading differences in dot blots, a cDNA probe corresponding to $3^{\prime}$ untranslated region of 28S ribosomal RNA (pA4) [26] was used as control.

\section{Library construction and differential screening}

Prior to poly (A) separation, equal amounts of total RNA was pooled from six individuals and from two different time points ( 4 and $12 \mathrm{~h}$ ) to maximize representation of different mRNA species in the library. Poly (A) RNA was then prepared using standard procedures [27], by one cycle of binding to oligo (dT)-cellulose column (Pharmacia, Uppsala, Sweden). $10 \mu \mathrm{g}$ poly (A) RNA from the RA-treated skin was used to construct a cDNA library in EcoRI cut Lambda Zap II cloning vector according to Stratagene protocols (La Jolla, CA). The library contained $6.2 \times 10^{6}$ primary plaques with an estimated $4 \%$ nonrecombinants. The remainder of poly (A) from both the RA- and vehicletreated control skin was converted into ${ }^{32} \mathrm{P}$-labeled single-stranded DNA probe by reverse transcription of mRNA as described [23, 27]. For screening, each radiolabeled probe was separately hybridized to each of the two replica filters (total of 20) prepared from the unamplified RA-treated library. Plaques showing different intensities of hybridization signal between the two probes were rescreened at lower densities and plaque purified by two subsequent differential screening as described above. RIS- 1 cDNA was rescued as a single-stranded DNA and converted into a circular plasmid using procedures described in Stratagene's manual. Plasmids were propagated and cDNA inserts were released by EcoRI digestion using established techniques [27].

\section{DNA sequencing}

RIS-1 cDNA was sequenced in both orientations and on both strands by dideoxy chain termination method [27], using the bluescript M13 reverse and M1321 primers and Sequenase (United States Biochemicals, Cleveland, $\mathrm{OH}$ ), as described [7]. The partial nucleotide sequence was compared by the method of Pearson and Lipman with sequences entered in Genbank, release \#71 and EMBL, release \#30.

\section{Southern blotting}

Human DNA (Clonetech Laboratories) and mouse DNA (a gift from Dr. David Burke, University of Michigan) were digested with restriction enzymes as indicated in figure legends and DNA blots were pre- pared using established protocols [27]. Southern blots were hybridized under conditions identical to those described for Northern blots [23], except for low stringency washes which were: 1) $2 \times \mathrm{SSC}, 0.1 \%$ SDS, at room temperature for $20 \mathrm{~min}, 2) 0.2 \times \mathrm{SSC}, 0.1 \% \mathrm{SDS}$ at $50^{\circ} \mathrm{C}$ for $30 \mathrm{~min}$.

\section{Statistical analysis}

Values obtained from RA- and vehicle-treated skin samples were normalized to the values of the $36 \mathrm{~B} 4$ control gene. The RA-treated values were then expressed as fold-change relative to vehicle-treated skin of the same individual for each time point. Because of the non-Gaussian distribution of the data, the median values and the 25- and 75-percentiles were assessed in all groups of observations. The significance of differences in RIS-1 mRNA levels between RA- and vehicle-treated skin was determined by the two-tailed Wilcoxon matched pairs test. Significance for induction ratios among time points for either RA- or vehicle-treated skin was ascertained by the two-tailed Mann-Whitney-U test and the Kruskal-Wallis test, as described [23].

\section{Results}

Isolation of RIS-1 cDNA from RA-treated library 20000 plaques from the unamplified RA-treated library were screened by differential hybridization with ${ }^{32} \mathrm{P}$-labeled single-stranded DNA probes derived from RA- and vehicle-treated skin. Multiple plaques exhibited a differential hybridization signal between the two probes, and eleven were chosen for further investigation. After two rounds of rescreening and plaque purification, three clones continued to show varying signal intensities (data not shown). One of these clones, RIS1 , was selected for further analysis. The ${ }^{32} \mathrm{P}$-labeled RIS- 1 cDNA insert detected a $0.6 \mathrm{~kb}$ mRNA species whose levels were modestly increased in RA-treated human skin Northern blots. These blots had been previously prepared from the same pooled RNA used to construct the RA-treated library. A subsequent screening of approximately 400000 lambda clones from the RAtreated library, using RIS- 1 as probe, resulted in identification of approximately 80 clones $(0.02 \%)$. These cDNA clones are currently being characterized. 

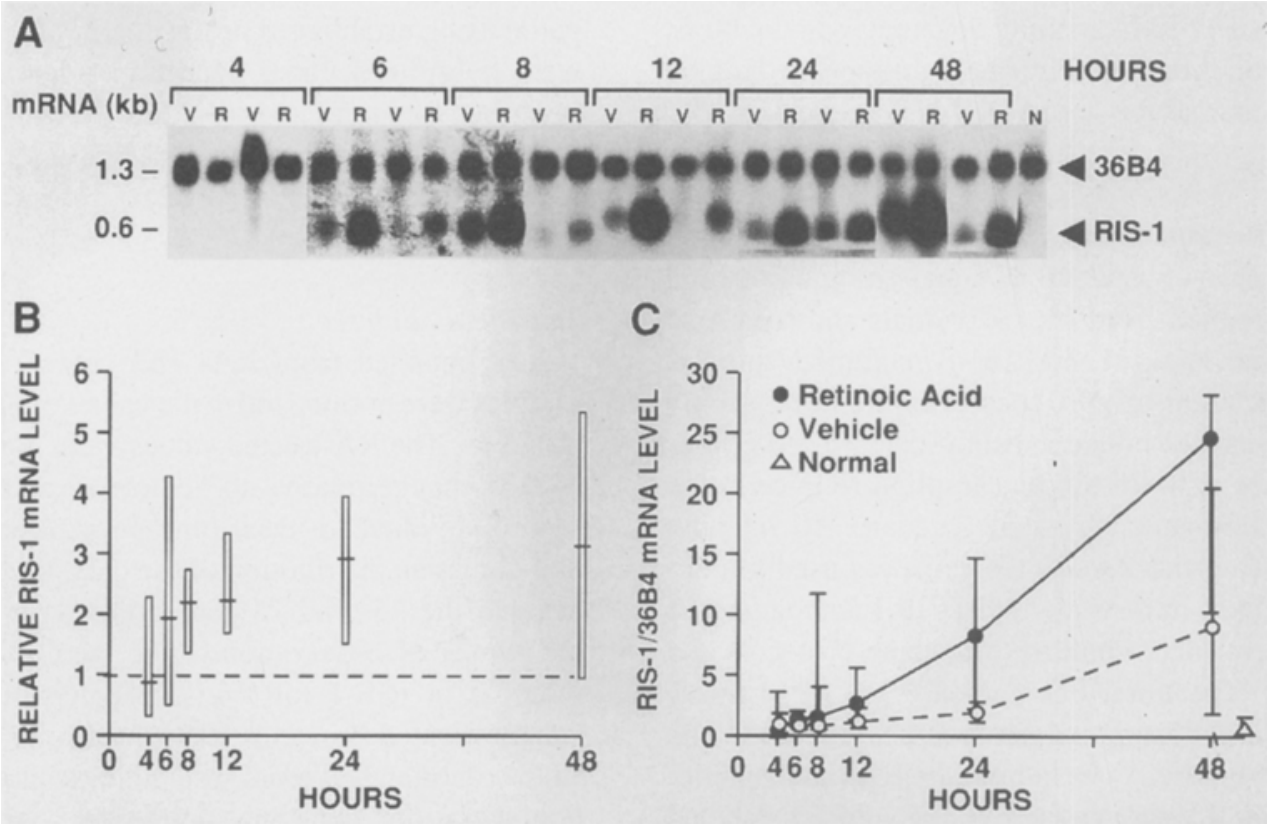

Fig. 1. Time course and kinetics of induction of RIS-1 mRNA in response to topical RA. (A) Volunteers were treated for indicated times with either vehicle cream (V) or $0.1 \% \mathrm{RA}$ cream (R) under occlusion with plastic wrap, or left untreated (N). Total RNA (30 $\mu \mathrm{g} / \mathrm{lane})$ was hybridized simultaneously against random-primed ${ }^{32} \mathrm{P}$-labeled cDNA probes for RIS-1 and 36B4 control gene. A representative RNA blot showing control-matched RNA samples for two individuals from each time points is shown. Only the relevant portion of the blot is presented with the size of mRNA species indicated on the left; (B) Values denote RIS-1 levels normalized to the control gene, expressed as fold-induction relative to matched, vehicle-treated skin. The median and 25 - and 75-percentile values are depicted $(4 \mathrm{~h}, \mathrm{n}=6 ; 6 \mathrm{~h}, \mathrm{n}=6 ; 8 \mathrm{~h}, \mathrm{n}=6 ; 12 \mathrm{~h}, \mathrm{n}=6$; $24 \mathrm{~h}, \mathrm{n}=5 ; 48 \mathrm{~h}, \mathrm{n}=5$; untreated normal skin, $\mathrm{n}=5$ ); (C) Integrated autoradiographic intensity of RA-treated and vehicle-treated skin from 'A' are shown separately as induction ratios after normalization to 36B4 mRNA levels The median and 25 - and 75-percentile values are depicted.

\section{Kinetics and time course of RIS-1 mRNA induction in human skin in vivo}

The kinetics and time course of induction of RIS-1 mRNA was next examined by Northern blotting of RNA from previously unexposed skin of additional volunteers treated with RA and its vehicle from 4 to $48 \mathrm{~h}$ (Fig. $1 \mathrm{~A}$ to $1 \mathrm{C}$ ). Of six individuals treated with RA and vehicle for $4 \mathrm{~h}$, RIS- 1 mRNA was undetectable in five but induced by 9 -fold in only one RA-treated individual. A relative increase of 1.9 fold (range $0.5-$ 5.4 fold, $n=6$ ) in RIS- 1 levels was seen by $6 \mathrm{~h}$ in RA-treated skin (Fig. 1B). RA treatment caused a significant increase in RIS-1 mRNA levels at $8 \mathrm{~h}$ (median 2.2 fold, range $1.1-3.6 ; n=6, p=0.028), 12 \mathrm{~h}(2.2$, $1.6-5.8 ; \mathrm{n}=6, \mathrm{p}=0.028), 24 \mathrm{~h}(2.9,1.3-5.5 ; \mathrm{n}=5$, $\mathrm{p}=0.043$ ), but not at $48 \mathrm{~h}$ (median 3.1 , range $0.8-7.5$ fold; $n=5, p=n s$ ) compared to vehicle-treated skin. The magnitude of increase in RIS-1 mRNA levels varied considerably between individuals. When values for RA-treated skin were normalized against the control gene, a marked temporal increase in RIS-1 mRNA levels was seen in all samples beginning at
$8 \mathrm{~h}$ (Fig. 1C). Vehicle treatment alone did not induce a significant increase in RIS- 1 transcript levels between 6-24 h but stimulated a modest rise in RIS- $1 \mathrm{mRNA}$ levels at $48 \mathrm{~h}$. This vehicle-mediated induction of RIS1 mRNA levels at later time points offset the expected higher relative values for RIS-1 in skin treated with RA for $48 \mathrm{~h}$ (compare Fig. 1B \& Fig. 1C).

Induction of RIS-1 gene expression coincides with the presence of RA and increased CRABP-II $M R N A$ levels in skin in vivo

To determine whether RIS-1 activation was RAdependent, we next analyzed the tissue concentrations of RA in skin in vivo by HPLC. Volunteers were treated with RA or vehicle for $4,6,8$ or 12 h spanning the time point (6-8 h) at which an increase in RIS-1 mRNA was first detected. RA was undetectable in skin treated with vehicle alone at all time points. RA treatment significantly increased RA levels in skin at 6,8 and $12 \mathrm{~h}(\mathrm{p} \leq 0.02)$ (Fig. 2A). The earliest time point at which significant RA levels were detected $(6 \mathrm{~h}$, median 56.5, range $18.8-120.6 \mathrm{ng} \mathrm{RA} / \mathrm{gm}$ wet wt tissue; 


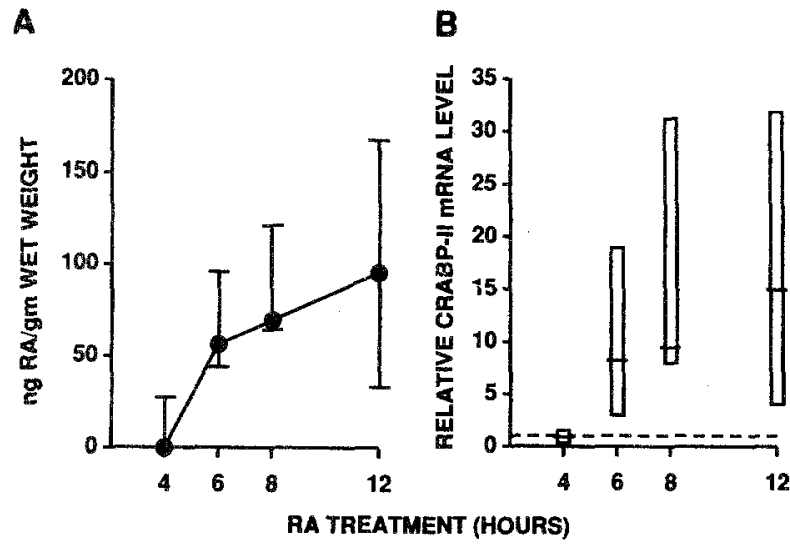

Fig. 2. RIS-1 activation coincides with the presence of RA and induction of CRABP-II mRNA in RA-treated skin in vivo. Volunteers were treated as described in legends to Fig. 1. The tissue samples were homogenized and examined: (A) by HPLC for RA content, and (B) by Northern blotting for CRABP-II mRNA levels RA concentration has been normalized to the gram wet weight of the tissue. The CRABP-II mRNA levels in RA-treated skin are normalized to the control gene cyclophilin and expressed as fold-induction relative to matched, vehicle-treated skin. The median and 25 - and 75-percentile values are depicted.

$n=9, p=0.02$ ) immediately preceded the time point $(8 \mathrm{~h})$ at which a significant increase in RIS-1 mRNA levels was first seen (compare Fig. 1 and Fig. 2A).

Because CRABP-II mRNA is markedly and specifically induced by topical RA in human skin [7, 9], and considered to be a marker of RA activity [28], we also measured CRABP-II mRNA levels at the time points indicated above. RA treatment significantly induced CRABP-II mRNA levels relative to vehicle-treated skin at $6 \mathrm{~h}$ (median 8.25 fold, range $1.6-19 ; \mathrm{n}=6$ ), and at $8 \mathrm{~h}$ and $12 \mathrm{~h}(\mathrm{p} \leq 0.007)$ (Fig. 2B).

\section{Tissue and cell type specific expression of RIS-I}

We next examined the tissue specific pattern of RIS-1 gene expression in RNA derived from several normal human tissues. As depicted in Fig. 3A, RIS-1 mRNA transcripts could not be detected in poly (A) RNA from any of the eight human tissues examined, even after prolonged autoradiographic exposure of blots. A strong hybridization signal was detected in all samples for 36B $4 \mathrm{mRNA}$ used as the control gene (Fig. 3A). As expected, a blot containing RNA from RA- and vehicle-treated skin which was simultaneously hybridized gave two bands of 0.6 and $1.3 \mathrm{~kb}$, corresponding to RIS-1 and 36B4 mRNA, respectively (Fig. 3A).

To determine RIS- 1 gene expression in cell types of human skin. RNA was extracted from untreated cultured cells and analyzed by dot blot hybridization using RIS-1 as probe. Dot blot analysis demonstrated the presence of RIS- 1 transcripts in untreated normal skin. Normal untreated cultured keratinocytes in vitro showed very low level expression of RIS-1 mRNA. No hybridization signal was apparent in dot-blotted RNA from cultured fibroblasts, melanocytes and a lymphocyte cell line (IM-9) (Fig. 3B), or in a Northern blot of poly (A) RNA from RA-treated F9 cells (Dr. J. Grippo, Hoffmann-La Roche, Inc.) (data not shown).

\section{Identity of RIS-1 cDNA and its sequence conservation}

The single RIS-1 clone isolated was approximately 209 nucleotides long. DNA sequencing of this cDNA showed an open reading frame of 49 amino acids followed by a TGA termination codon, a canonical AUAAA, and a long stretch of poly (A) tail at the $\mathrm{C}$-terminus. Computer-assisted analysis of the derived 49 amino acid sequence predicted a polypeptide of $5.7 \mathrm{kDa}$. However, since RIS-1 cDNA clone does not appear to be full length, the actual size of the encoded protein will probably be larger. A search of gene data bank did not reveal homology between the sequence of RIS-1 and other known RA-inducible genes. However, RIS-1 sequence was found to exhibit homology to amino acids 54-102 of 'psoriasin', a gene reportedly overexpressed in psoriatic epidermis [29]. The two regions of homology were identical except for a $\mathrm{C}$ $>\mathrm{T}$ conversion at the nucleotide position 266 in psoriasin (58 in RIS-1). The first 29 amino acids of RIS1 also exhibited $44 \%$ homology to the EF-hand type calcium binding domain of calmodulin type [30]. To examine the genomic organization and sequence conservation of RIS- 1 in mammalian species, a randomprimed RIS-1 cDNA probe lacking PstI, HindIII and BamHI restriction sites was hybridized to the human and mouse genomic DNA digested with the corresponding enzymes. This revealed several hybridizing bands (Fig. 4), suggesting the existence of conserved RIS- 1 sequences in these species.

\section{Discussion}

This paper describes isolation of a cDNA representing an early retinoic acid-induced gene whose expression is restricted to $s \mathrm{kin}$ (RIS-1). While the possible function of RIS- 1 in mediating cutaneous effects of RA can not be addressed at present, several lines of evidence 


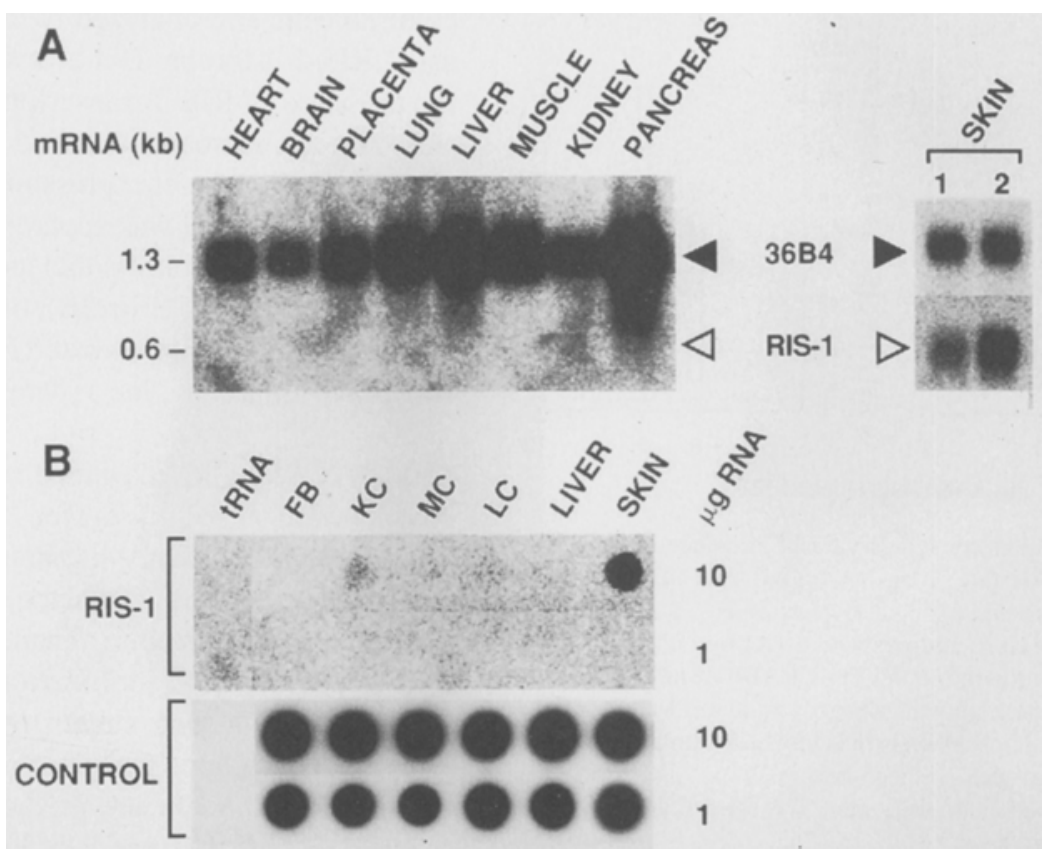

Fig. 3. Restricted expression of RIS- 1 mRNA in human tissues and cultured cells. (A) cDNA probes for RIS-1 and $36 \mathrm{~B} 4$ were ${ }^{32} \mathrm{P}-1 \mathrm{abeled}$ to similar specific activity and simultaneously hybridized to $2.5 \mu \mathrm{g}$ poly (A) RNA extracted from human tissues. As a positive control, a RNA blot prepared from vehicle-treated (1) and RA-treated (2) skin was also included in the hybridization (right panel). After simultaneous hybridization for $18 \mathrm{~h}$, blots were washed under both low and high stringency and examined for RIS-1 and 36B4 gene expression; (B) Total RNA was isolated from untreated cultured human cells and 1 and $10 \mu \mathrm{g}$ RNA was analyzed by dot blot hybridization to ${ }^{32}$ P-labeled RIS-1 insert. RNA from human skin and liver served as positive and negative controls, respectively. The cell types are indicated at the top: FB, fibroblasts; KC, keratinocytes; MC, melanocytes, and LC, IM-9 lymphocytes. After removal of RIS-1 probe, the filter was subsequently hybridized to a 285 ribosomal probe to determine equal RNA loading (lower panel in 3B).

strongly suggest that induction of RIS-1, at least at earlier time points, may be specifically mediated by RA. First, RIS-1 mRNA was barely detectable in normal, vehicle- and RA-treated skin in which no measurable amounts of RA ( $\leq 1 \mathrm{ng} / \mathrm{gm}$ wet wt tissue) were found. This was consistent with the notion that the presence of RA was required for RIS-1 gene activation in vivo. This RA-dependence was also evidenced by a continued rise in RIS- 1 transcript levels during the entire time course of treatment. Secondly, the average concentrations of RA detected in skin specimens after $6 \mathrm{~h}$ treatment in vivo were comparable to levels capable of activating RAR/RXR receptors in cotransfection assays in vitro [21]. We found that the RA concentration was approximately 180 -fold higher than $\mathrm{ED}_{50}$ values for $\mathrm{RAR}-\tau, 60$-fold higher than $\mathrm{ED}_{50}$ for $\operatorname{RAR}-\beta, 10$-fold higher than $\mathrm{ED}_{50}$ for $\mathrm{RAR}-\beta$, and equal to $\mathrm{ED}_{50}$ for RXR- $\alpha$, all of which are expressed at varying levels in human skin cells [7-9]. Thus, our data suggest, but do not prove, that RIS-1 gene might be directly regulated by RA/RA receptor complex interacting with potential cis-acting element(s) present in the RIS- 1 gene. Finally, RIS-1 mRNA induction was concomitant with a marked increase in CRABP-II mRNA levels in RAtreated skin. Increased CRABP-II expression following RA treatment is consistent with the presence of RARE in the $5^{\prime}$ flanking region in the CRABP-II gene [31]. Although the precise role of CRABP-II in mediating the effects of RA in skin is unknown, recent in vivo studies have shown that CRABP-II mRNA response is an indicator of retinoid activity in mouse [14] and human skin [28]. Therefore, it is interesting to note that RIS-1 mRNA activation coincides with both the accumulation of RA in skin layers and induction of a $\mathrm{RA}$ responsive gene, CRABP-II.

To minimize the possibility of cloning genes that might be induced by mild retinoid-induced irritation, the time points for construction of the RA-treated library were selected so as to allow for RA absorption and penetration through skin layers before the appear- 


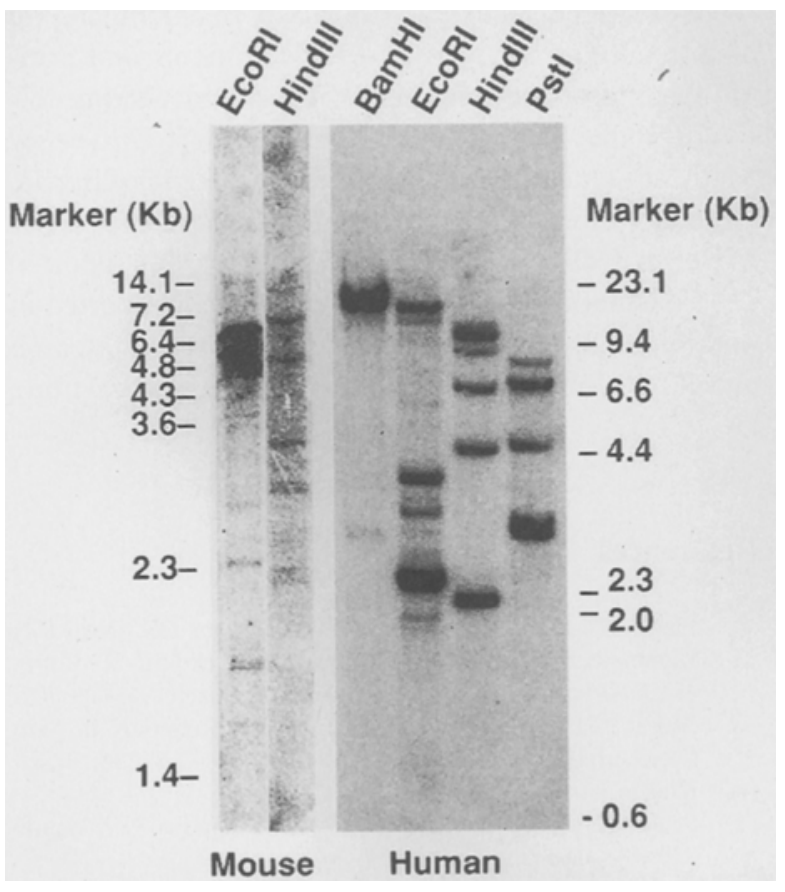

Fig. 4. Analysis of human and mouse chromosomal DNA for homologous sequences to RIS-1 cDNA. High molecular weight DNA from either mouse or human DNA was digested with various restriction enzymes shown at the top. Samples $(10 \mu \mathrm{g})$ were electrophoresed, blotted and hybridized to a random-primed ${ }^{32} \mathrm{P}$-labeled RIS-1 cDNA insert and washed at $02 \times \mathrm{SSC}$, at $50^{\circ} \mathrm{C}$ for $30 \mathrm{~min}$. Size markers for mouse and human DNA are shown on the left and right, respectively, More stringent washes in $02 \times \mathrm{SSC}$ at $60^{\circ} \mathrm{C}$ for $30 \mathrm{~min}$ had no effects on the hybridization pattern of RIS-1 to human DNA but totally abrogated the signal in mouse genomic DNA digest (data not shown).

ance of a clinical erythema. This was confirmed by histological evaluation of several 4-mm punch biopsies from the treated skin areas. Consistent with this approach, vehicle treatment of skin for an extended period of time (4-24 h) did not stimulate RIS-1 steady state mRNA levels. Our findings are also compatible with a recent study demonstrating that topical application of RA and vehicle for up to $24 \mathrm{~h}$ did not induce erythema or any inflammatory response in human skin [28]. Prolonged vehicle treatment (48 h), however, modestly increased RIS-1 mRNA levels in some individuals. Whether or not this increased RIS-1 mRNA level in vehicle-treated skin was simply related to occasional subcutaneous diffusion of RA to adjacent tissue areas or was the result of involvement of secondary mediators will require further investigation. For example, recent work has demonstrated that disruption of skin layers using agents such as sodium dodecyl sul- fate (SDS) [32], application of organic solvents [33], and abrasion [34] produces an irritant response similar to that observed in 4-day RA-treated skin $[1,28]$. We have found no variations in RIS- 1 transcript levels between vehicle and SDS treated human skin at several time points (manuscript in preparation). A better understanding of possible vehicle effects on RIS1 gene expression will require the analysis of RIS-1 induction in response to well-defined vehicle components.

Both the induction of transcription and/or the accumulation of message might be responsible for the elevated RIS- 1 mRNA levels seen in RA-treated skin. The rapid induction of RIS-1 mRNA in RA-treated skin in vivo is reminiscent of other RA-induced genes some of which are trans-acting transcription factors. Several RA early response genes, Era-1/HOX 1.6 [18], MK-1 [35], and zif268 [36] have been isolated from various tissues and cell types but not from adult human skin. Because, the RIS-1 sequence is not homologous to these or any other widely distributed transcription factors such as AP-1 [37], its function, if any, is presumably restricted to skin. Another possibility is that RIS-1 represents a skin-specific accessory molecule acting either alone or in concert with the RAR/RXR to regulate expression of a distinct set of RA target genes in skin. Theoretically, an indirect mechanism of RA responsiveness could result from the induction of an intermediary activator protein such as RIS-1.

Based on the mRNA size of $0.6 \mathrm{~kb}$, we would predict RIS-1 to encode a polypeptide of approximately 8 to $9 \mathrm{kDa}$. Alignment of the peptide sequence derived from the partial RIS-1 cDNA exhibited a low homology $(44 \%)$ with the consensus sequence of the EF-hand type present in several calcium binding proteins [30]. The significance of this homology and whether or not RIS-1 protein actually binds $\mathrm{Ca}^{2+}$ either in vivo or in vitro remains to be determined. Interestingly, we found that the partial RIS-1 cDNA was nearly identical to psoriasin, a gene recently isolated from the skin of psoriasis patients [29]. Although psoriasin overexpression was previously suggested to be associated with the psoriasis phenotype, more recent work [38] has not confirmed the original report. Thus, it appears that the name 'psoriasin' might be a misnomer as transcripts for this gene are also found in other inflammatory skin conditions [38]. Because our cDNA was truncated at the $5^{\prime}$ terminus, it was not possible to compare its amino terminal sequence with the corresponding region in psoriasin. It is noteworthy, however, that the estimated size of RIS- 1 mRNA (600 nt) 
differs considerably from that of psoriasin which was reported to be 1000 nucleotides long [29]. One possibility for this discrepancy is that the RIS- 1 mRNA reported here is a splicing variant derived from the psoriasin gene. However, because we observed only a single hybridizing band in the Northern blots, this does not appear to be likely. Another possibility is that RIS-1 and psoriasin are two related transcripts with divergent $5^{\prime}$ but identical $3^{\prime}$ coding sequences. The presence of several hybridizing bands in the Southern blot of human genomic DNA (also see below) might sustain this idea. Alternatively, the variation in mRNA size for RIS-1 and psoriasin may be simply due to the different methods used for their estimation in Northern blots. We always include RNA markers in our Northern gels that are subsequently marked on filters and used for accurate sizing of an unknown mRNA. Thus, assuming that RIS- 1 and psoriasin are the same gene products, a possibility we strongly favor, it is likely that our estimation of a mRNA of $600 \mathrm{nt}$ is actually the correct size for RIS-1/psoriasin.

The fact that RIS- 1 cDNA probe used in this work was only 209 nucleotides long implies that it probably corresponds to one or two exons of RIS-1 gene. Therefore, the complex hybridization profile of RIS-1 in both human and mouse genomic DNA digests suggests either, (1) the existence of several RIS-1 pseudogenes in the genome, or (2) that RIS-1 belongs to a family of potentially RA-inducible genes, or perhaps both.

Regardless of its function, the rapid induction and tissue-specific expression of RIS-1 in vivo, together with its RA-dependence, strongly suggest that RIS-1 may be a target of RA action in skin. These findings implicate RIS-1/psoriasin as another gene similar to CRABP-II [28] which is known to be induced by topical RA and also elevated in psoriasis, a disease characterized by altered epidermal differentiation. Clearly, further work is needed to determine if RIS-1/psoriasin is a direct or indirect target of all-trans RA in skin.

\section{Acknowledgments}

We thank Karen Keane, Susan Foltin and Angela Fishman for excellent technical assistance; Dr. Christopher Griffiths and Robin Gardner for procurement of human skin biopsies, and Ted Hamilton for help with the statistical analysis of data. The authors are grateful for the Southern blot of mouse genomic DNA kindly provided by Dr. David Burke and Roxanne Tavakkol, Depart- ment of Human Genetics, University of Michigan. We also thank Dr. David Burke for comments and critical reading of the manuscript. CCZ is a visiting fellow from the Department of Dermatology, University Medical Center Steglitz, The Free University of Berlin, Germany and supported in part by The Free University of Berlin. CCZ acknowledges the invaluable support of Dr. Constantine Orfanos. This work was supported in part by the Babcock Fund for dermatological research and R. W. Johnson Pharmaceutical Research Institute (AT, ED).

\section{References}

1. Fisher JG, Esmann J, Griffiths CEM, Talwar HS, Duell EA, Hammerberg C, Elder JT, Karabin GD, Nickoloff BJ, Cooper KD \& Voorhees JJ (1991) J. Invest. Dermatol. 96: 699-707.

2. Saurat J-H (1989) in: Pharmacology of Retinoids in Skin (Reichert U and Shroot B, eds), vol. 3, pp. 215-226, Basel, Krager

3. Petkovich M, Brand NJ, Krust A \& Chambon P (1987) Nature 330: 444-450

4. Gigueref V, Ong ES, Segui P \& Evans RM (1987) Nature 330: 624-629

5. Hoffmann B., Lehmann JM, Zhang XK, Hermann T, Husmann M, Graupner G \& Pfahl M (1990) Mol. Endo. 4, 17271736

6. Dolle P, Ruberte E, Kastner P, Petkovich M, Stoner CM, Gudas IJ \& Chambon P (1989) Nature 342, 702-705

7. Tavakkol A, Griffiths CEM, Keane KM, Palmer RD \& Voorhees JJ (1992) J. Invest. Dermatol. 99, 146-150

8. Redfern CPF \& Todd C (1992) J Cell Sci. 102, 113-121

9. Elder JT, Åström A, Tavakkol A, Krust A, Kastner P, Chambon P \& Voorhees JJ (1992) J. Invest. Dermatol. 98, 36S-41S

10. Ong DE \& Chytil F (1978) J. Biol. Chem. 253, 4551-4554

11. Nilsson MHL, Spurr NK, Saksena P, Busch C, Norlinder H, Peterson PA \& Sundelin J (1988) Biochemistry 173, 45-5 I

12. Aström A, Tavakkol A, Peterson U, Cromie M, Elder JT \& Voorhees JJ (1991) J Biol Chem 266, 17662-17666

13. Eller MS, Oleksiak MF, McQuaid TJ, McAfee SG \& Gilchrest BA (1992) Exp. Cell. Res. 199, 328-336

14. Reynolds NJ, Fisher GJ, Griffiths CEM, Tavakkol A, Talwar HS, Rowse PE, Hamilton TA \& Voorhees JJ (1993) J Pharmacol. Exp. Therap. 266, 1636-1642

15. Maden M, Ong DE, Summerbell D \& Chytyl F (1988) Nature $335,733-735$

16. Bedo G, Santisteban P \& Aranda A (1989) Nature (London) 339, 231-234

17. Lucas PC, O'Brein RM, Mitchell JA, Davis CM, Imai E, Forman BM, Samuels HH \& Granner DK (1991) Proc. Natl. Acad. Sci. USA $88,2184-2188$

18. LaRosa GJ \& Gudas LJ (1988) Proc. Natl. Acad. Sci. USA, $85,329-333$

19. Duester G, Shean Ml, McBride MS \& Stewart MJ (1991) Mol Cell. Biol. 11, 1638-1646

20. Gudas LJ (1992) Cell Growth Diff 3, 652-662

21. Duell ED, Aström A, Griffiths CEM, Chambon P \& Voorhees JJ (1992) J. Clin. Invest. 90, 1269-1274 
22. Lowry OH, Rosebrough NJ, Farr AL \& Randall RJ (1951) J. Biol. Chem. 193, 265-275

23. Zouboulis CC \& Tavakkol A (1994) BioTechniques 16, 290294

24. Laborda, J (1991) Nucl. Acids Res. 19, 3998

25. Danielson PE, Forss-Petter S, Brow MA, Calavetta L, Douglass J, Milner RJ \& Sutcliffe JG (1988) DNA 7, 261-267

26. Gonzalez IL, Gorski JL, Campen TJ, Dorney DJ, Erickson JM, Sylvestor JE \& Schmickel RD (1985) Proc. Natl. Acad. Sci. USA $82,7666-7670$

27. Sambrook J, Fritsch EF \& Maniatis T (1989) Molecular Cloning: A laboratory Manual, 2nd Ed., Cold Spring Harbor, New York

28. Elder JT, Cromie M, Griffiths CEM, Chambon P \& Voorhees JJ (1993) J Invest Dermatol 100, 356-359

29. Madsen P, Rasmussen HH, Leffers H, Honore B, Dejgaard K, Olsen E, Kiil J, Walbum E, Anderson AH, Basse B, Lauridsen JB, Ratz GP, Celis A, Vandekerckhove J \& Celis JE (1991) J. Invest. Dermatol. 97, 701-712
30. Kretsinger RH (1987) Cold Spring Harbor Symposia on Quantitative Biology 52, 499-510

31. Durand B, Saunders M, Leroy P, Leid M \& Chambon P (1992) Cell $71,73-85$

32. Anger $\mathrm{T}$ (1991) Contact Dermatitis 25, 108-114

33. Proksch E, Feingold KR, Mao-Qiang M \& Elias PM (1991) J Clin. Invest. 87, 1668-1673

34. Marks R, Hill S \& Barton SP (1990) Br. J. Dermatol. 123, $457-466$

35. Kodomatsu K, Tomokura M \& Muramatsu T (1988) Biochem. Biophys. Res. Commun. 151, 1312-1316

36. Suva II, Ernst M \& Rodan GA (1991) Mol. Cell. Biol. 5, 2503-2510

37. Angel P, Allegretto EA, Okino ST, Hattori K, Boyle WJ, Hunter T \& Karin M (1988) Nature 332, 166-171

38. Sitzmann J, Algermissen B, Czarnetzki BM \& LeMotte P (1993) J. Invest. Dermatol. 100, 220 